To submit in Vehicle System Dynamics

Vol. 00, No. 00, Month 20XX, 1-24

\title{
Enhancing roll stability of heavy vehicle by LQR active anti-roll bar control using electronic servo-valve hydraulic actuators
}

\author{
Van-Tan $\mathrm{Vu}^{\mathrm{a}},{ }^{\mathrm{c} *}$, Olivier Sename ${ }^{\mathrm{a}}$, Luc Dugard ${ }^{\mathrm{a}}$ and Peter Gaspar ${ }^{\mathrm{b}}$ \\ ${ }^{a}$ Univ. Grenoble Alpes and CNRS, GIPSA-lab, F-38402 Grenoble Cedex, France; ${ }^{b}$ Systems and \\ Control Laboratory, Institute for Computer Science and Control, Hungarian Academy of \\ Sciences, Kende u. 13-17, H-1111 Budapest, Hungary; ${ }^{c}$ Department of Automotive Mechanical \\ Engineering, University of Transport and Communications. No.3 Cau Giay St., Lang Thuong \\ Ward, Dong Da District, Hanoi, Vietnam
}

(Received 00 Month 20XX; accepted 00 Month 20XX)

\begin{abstract}
Rollover of heavy vehicle is an important road safety problem world-wide. Although rollovers are relatively rare events, they are usually deadly accidents when they occur. The roll stability loss is the main cause of rollover accidents in which heavy vehicles are involved. In order to improve the roll stability, most of modern heavy vehicles are equipped with passive anti-roll bars to reduce roll motion during cornering or riding on uneven roads. However these may be not sufficient to overcome critical situations. This paper introduces the active anti-roll bars made of four electronic servo-valve hydraulic actuators, which are modelled and integrated in a yaw-roll model of a single unit heavy vehicle. The control signal is the current entering the electronic servo-valve and the output is the force generated by the hydraulic actuator. The active control design is achieved solving a linear optimal control problem based on the Linear Quadratic Regulator $(L Q R)$ approach. A comparison of several $L Q R$ controllers is provided to allow for tackling the considered multi-objective problems. Simulation results in frequency and time domains show that the use of two active anti-roll bars (front and rear axles) drastically improves the roll stability of the single unit heavy vehicle compared with the passive anti-roll bar.
\end{abstract}

Keywords: Active anti-roll bar control, electronic servo-valve hydraulic actuator, rollover, roll stability, $L Q R$ control.

\section{INTRODUCTION}

\subsection{Background}

The rollover is a very serious problem for heavy vehicle safety, which can result in large financial and environmental consequences. Rollover accidents are classified into four categories: preventable, potentially preventable, non-preventable and preventable unknown [1]. It is usually difficult for the driver to feel the rollover behaviour of a heavy vehicle. Investigations have shown that only a minority of rollover accidents could have been avoided with a warning device, potentially more with a skilled driver, but half of the rollover accidents were not preventable by driver action alone.

The three major contributing factors to rollover accidents are side wind gusts, abrupt steering and braking manoeuvres by the driver. The main cause of rollover accidents in

\footnotetext{
* Corresponding author. Email: Van-Tan.Vu@gipsa-lab.grenoble-inp.fr
} 
which heavy vehicles are involved is the roll stability loss when the tyre-road contact force on one of the side wheels becomes zero. Roll stability refers to the ability of a vehicle to overcome overturning moments generated during cornering and lane changing. It is well known that heavy vehicles do have relatively high centres of mass and narrow track widths and can loose roll stability at moderate levels of lateral acceleration [2].

Most heavy vehicles are equipped with passive anti-roll bars in all axles in order to improve roll stability. The passive anti-roll bar force is applied at each side of the vehicle so that the left force has the same magnitude as the right one, but in the opposite direction. The passive anti-roll bar has the advantage to reduce the body roll acceleration and roll angle during single wheel lifting and cornering manoeuvres. By reducing body roll motion, the driving safety and roll stability are highly improved. However, passive anti-roll bars do have drawbacks. During cornering manoeuvres, the anti-roll bar will transfer the vertical forces of one side of the suspension to the other one, creating therefore a yaw moment [3]. This highlights the need for an active safety system in heavy vehicles.

In order to overcome such drawbacks, several schemes concerned with the possible active intervention onto the vehicle dynamics have been proposed as follows: active steering, active brake, active suspension and active anti-roll bars. Among them, the most common method used to improve the roll stability is the active anti-roll bar.

Active anti-roll bars are usually made of a pair of hydraulic actuators. Lateral acceleration makes vehicles with conventional passive suspension tilt out of corners. The center of the sprung mass shifts outboard of the vehicle centerline, which creates a destabilizing moment that degrades roll stability. The lateral load response is reduced by active antiroll bars that generate a stabilizing moment to counterbalance the overturning moment in such a way that the control torque leans the vehicle into the corners [4], [5].

One drawback of active anti-roll bars is that the maximum stabilizing moment is limited physically by the relative roll angle between the body and the axle [6].

\subsection{Related works}

Rollover prevention using active anti-roll bar has been the topic of research studies for more than 20 years. Several models and control methods have been used for the two main types of heavy vehicles: single unit heavy vehicle [4], [7] and long combination heavy vehicles [8], [9]. However, the long combination heavy vehicles are beyond the scope of this paper.

\subsubsection{Models of heavy vehicle}

Two main models are used to study active anti-roll bars on single unit heavy vehicles: the Roll model [1], [10], [11] and the Yaw-Roll model [7], [12]. In Miege et al [1], the roll model of heavy vehicle is considered with a servo-valve hydraulic actuator and the input control signal is the spool valve displacement of the servo-valve. However such a model cannot be used to assess the entire behavior of the single unit heavy vehicle.

Most studies on active anti-roll bar systems use the yaw-roll model with the force (or torque) as the input control signal [2], [4]. This model has been proven to be stable and consistent with the behavior of the single unit heavy vehicle. Nevertheless it still lacks accuracy since no actuator model is included. 


\subsubsection{Control methods for the active anti-roll bar system on heavy vehicles}

Some of the control methods applied for active anti-roll bar control on heavy vehicles are briefly presented below:

a- Optimal control: Sampson et al [6], [13] and Miege et al [9] proposed a state feedback controller which was designed by finding an optimal controller based on a linear quadratic regulator $(L Q R)$ for single unit and articulated heavy vehicles. They used the control torques acting between the axle groups and the sprung mass as the input control signal. This led to reducing steady state and peak transient load transfer significantly when compared to a passive vehicle. The influence of frame flexibility on the controller design was also investigated.

$\mathrm{H}$. $\mathrm{Yu}$ et al [10] proposed a rollover threat warning system that uses the real-time dynamic model-based time-to-rollover metric as a basis for online rollover detections. The simulations performed using TruckSim indicated that a rollover threat detection system was further enhanced in combination with an active roll control system using active suspension mechanism. This was done by designing an optimal control strategy $(L Q R)$, able to improve the dynamic roll stability in vehicle curving and emergency driving situations.

b- Neural network control: Boada et al [2] and Babesse et al [14] proposed a reinforcement learning algorithm using neural networks to improve the roll stability for a single unit heavy vehicle. The input control signals are the torques at the axles. Even if such a control approach shows good performances in simulation and can adapt to changes produced in the environment, it is however not suitable for embedded control.

c- Robust control ( $L P V)$ : Gaspar et al [4], [12], [15] applied the Linear Parameter Varying $(L P V)$ approach for active anti-roll bars combined with active brake control on single unit heavy vehicles. They also used a Fault Detection and Identification (FDI) filter, which identifies different actuator failures. The forward velocity was considered as the varying parameter.

The $H_{\infty}$ control method was also applied to the yaw-roll model of a single unit heavy vehicle. The input control signal is the torque generated by the actuators [16]. Performance analysis in the frequency and time domains have shown that $H_{\infty}$ active anti-roll bar control drastically reduces the normalized load transfer compared with passive anti-roll bars. It is also shown, using $\mu$-analysis, that the $H_{\infty}$ active anti-roll bar control is robust w.r.t. forward velocity and sprung mass variations.

\subsection{Paper contribution}

Based on the yaw-roll model presented in [4], this paper proposes an integrated model with four electronic servo-valve hydraulic actuator models in a single unit heavy vehicle yaw-roll model. Then the $L Q R$ control method is applied to the active anti-roll bar and focuses on showing how it can provide a wide set of solutions to solve the multiobjective problem for the improvement of the roll stability, while taking into account the characteristics of the electronic servo-valve hydraulic actuators. Hence, the contributions of the paper are the following:

- An integrated model, including four electronic servo-valve hydraulic actuator models in a single unit heavy vehicle yaw-roll model, is proposed to control the spool valve displacements that distribute high pressure oil into two chambers of the hydraulic cylinders. The input currents of the electronic servo-valve hydraulic actuators are controlled to generate the force in various manoeuvre situations. The use of four electronic 
servo-valve hydraulic actuators in a yaw-roll model of a single unit heavy vehicle is an evolution, compared to previous studies.

- An optimal $L Q R$ is developed, where the optimal criterion is formulated from vehicle dynamics specifications in terms of roll stability. A generic definition of the control objectives is proposed to cope with most of the industrial performance requirements for heavy vehicles dynamics control.

- A detailed comparison of several tunings of the $L Q R$ controllers is provided in order to emphasize how they can cope with multi-objective requirements in terms of roll stability (normalized load transfer) and actuator constraints (input current limitations).

- The simulation results show that the $L Q R$ active anti-roll bar control using four electronic servo-valve hydraulic actuators drastically improves the roll stability of the single unit heavy vehicle throughout the main frequency range compared with passive anti-roll bar. It also allows the assessment of the effects of the induced normalized load transfer, of the input current limitations, as well as of the operation of the electronic servo-valve hydraulic actuators.

The paper is organised as follows: section 2 details the integrated model of heavy vehicles which includes four electronic servo-valve hydraulic actuators and a linear single unit heavy vehicle yaw-roll model. Section 3 proposes three $L Q R$ active anti-roll bar controls of the electronic servo-valve hydraulic actuators, whose objective is to maximize the roll stability of the heavy vehicle while considering the actuators constraints. Section 4 gives a simulation results analysis in frequency and time domains where the $L Q R$ active anti-roll bar controllers are compared with the passive anti-roll bar case. The effect of the forward velocity on the closed-loop system is analysed in section 5 . Finally, some conclusions are drawn in section 6.

\section{INTEGRATED MODEL OF SINGLE UNIT HEAVY VEHICLE}

The proposed integrated model includes four electronic servo-valve hydraulic actuators (two at the front axle and two at the rear axle) in a linear single unit heavy vehicle yawroll model. The control signal is the electrical current $u$ opening the electronic servo-valve, the output is the force $F_{a c t}$ generated by the hydraulic actuator. In the next section, the model of the considered controlled hydraulic actuator is presented.

\subsection{Electronic servo-valve hydraulic actuator model}

Figure 1 illustrates the diagram of the considered electronic servo-valve hydraulic actuator, made of an electronic servo-valve (or proportional valve) and of a hydraulic cylinder.

The spool valve of the electronic servo-valve is controlled by a current which generates a displacement $X_{v}$. The oil supply high pressure $P_{s}$ is always stored outside the electronic servo-valve and the moving spool valve distributes high pressure oil into two chambers of the hydraulic cylinder. The difference of pressure $\Delta P=P_{1}-P_{2}$ of the two chambers produces the output force $F_{\text {act }}$ given by:

$$
F_{a c t}=A_{P} \Delta P
$$

where $A_{P}$ is the area of the piston.

The servo-valve orifices are assumed to be matched and symmetrical so that the load 


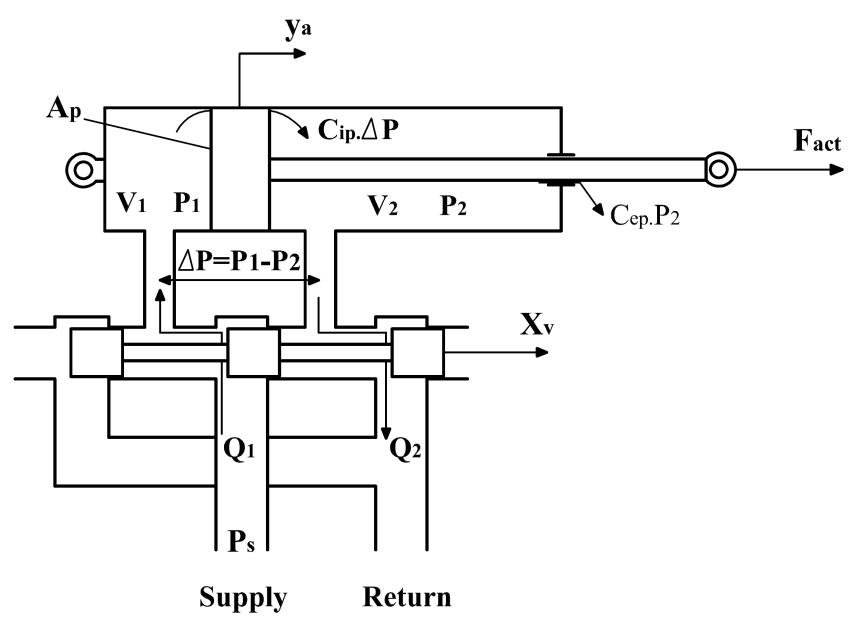

Figure 1. Diagram of the electronic servo-valve hydraulic actuator [17].

flow $Q_{L}$ is computed as follows [1], [17]:

$$
Q_{L}=\frac{Q_{1}+Q_{2}}{2}=K_{x} X_{v}-K_{P} \Delta P
$$

where $K_{x}$ and $K_{P}$ are the valve flow gain and pressure coefficients, respectively. The equations for each chamber can be written as:

$$
\left\{\begin{array}{l}
\frac{d V_{1}}{d t}+\frac{V_{1}}{\beta_{e}} \frac{d P_{1}}{d t}=Q_{1}-C_{i p}\left(P_{1}-P_{2}\right)-C_{e p} P_{1} \\
\frac{d V_{2}}{d t}+\frac{V_{2}}{\beta_{e}} \frac{d P_{2}}{d t}=C_{i p}\left(P_{1}-P_{2}\right)-C_{e p} P_{2}-Q_{2}
\end{array}\right.
$$

where $\beta_{e}$ is the effective bulk modulus of the oil, $C_{e p}$ and $C_{i p}$ are the external and internal leakage coefficients of the actuator.

The volume in each chamber varies with the piston displacement $y_{a}$ as:

$$
\left\{\begin{array}{l}
V_{1}=V_{01}+A_{p} y_{a} \\
V_{2}=V_{02}-A_{p} y_{a}
\end{array}\right.
$$

where $V_{01}$ and $V_{02}$ are the initial volumes in each chamber. Assuming that $V_{01}=V_{02}=V_{0}$, the total volume of trapped oil is given by:

$$
V_{t}=V_{1}+V_{2}=V_{01}+V_{02}=2 V_{0}
$$

Therefore, the equations in each chamber become:

$$
\left\{\begin{array}{l}
A_{p} \frac{d y_{a}}{d t}+\frac{V_{0}+A_{p} y_{a}}{\beta_{e}} \frac{d P_{1}}{d t}=Q_{1}-C_{i p}\left(P_{1}-P_{2}\right)-C_{e p} P_{1} \\
-A_{p} \frac{d y_{a}}{d t}+\frac{V_{0}-A_{p} y_{a}}{\beta_{e}} \frac{d P_{2}}{d t}=C_{i p}\left(P_{1}-P_{2}\right)-C_{e p} P_{2}-Q_{2}
\end{array}\right.
$$

Subtracting the second equation to the first one leads to:

$$
Q_{1}+Q_{2}=2 C_{t p} \Delta P+2 A_{p} \frac{d y_{a}}{d t}+\frac{V_{0}}{\beta_{e}} \frac{d \Delta P}{d t}
$$


Table 1. Parameters of the electronic servo-valve hydraulic actuator [1], [18].

\begin{tabular}{llll}
\hline Symbols & Description & Value & Unit \\
\hline$A_{P}$ & Area of the piston & 0.0123 & $\mathrm{~m}^{2}$ \\
$K_{x}$ & Valve flow gain coefficient & 2.5 & $\mathrm{~m}^{2} / \mathrm{s}$ \\
$K_{P}$ & Total flow pressure coefficient & $4.2 \times 10^{-11}$ & $\mathrm{~m}^{5} /(\mathrm{Ns})$ \\
$C_{t p}$ & Total leakage coefficient of the actuator & 0 & - \\
$V_{t}$ & Total volume of trapped oil & 0.0014 & $\mathrm{~m}^{3}$ \\
$\beta_{e}$ & Effective bulk modulus of the oil & $6.89 \times 10^{6}$ & $\mathrm{~N} / \mathrm{m}^{2}$ \\
$\tau$ & Time constant of the servo-valve & 0.01 & $\mathrm{~s}$ \\
$K_{v}$ & Servo-valve gain & 0.0239 & $\mathrm{~m} / \mathrm{A}$ \\
\hline
\end{tabular}

where $C_{t p}=2 C_{i p}+C_{e p}$ is the total leakage coefficient of the actuator.

From equations (2) and (7), the dynamic equation of the servo-valve hydraulic actuator is obtained as follows:

$$
\frac{V_{t}}{4 \beta_{e}} \frac{d \Delta P}{d t}+\left(K_{P}+C_{t p}\right) \Delta P-K_{x} X_{v}+A_{P} \frac{d y_{a}}{d t}=0
$$

where $y_{a}$ is the displacement of the piston of the hydraulic actuator.

Besides, the displacement of the spool valve $X_{v}$ is controlled by the electrical current $u$. The effects of hysteresis and flow forces on the servo-valve are here neglected, then the dynamical behavior of the electronic servo-valve can be approximated by a first-order model [18], [19], as:

$$
\frac{d X_{v}}{d t}+\frac{1}{\tau} X_{v}-\frac{K_{v}}{\tau} u=0
$$

where $\tau$ is the time constant and $K_{v}$ the gain of the servo-valve model.

To summarize, the equations (1), (8), (9) model the electronic servo-valve hydraulic actuator, where the input signal is the current $u$ and the output is the force $F_{\text {act }}$. The parameters of the model are shown in Table 1.

\subsection{Yaw-roll model of single unit heavy vehicle}

Fig 2 illustrates the combined yaw-roll dynamics of the vehicle modeled by a three-body system, in which $m_{s}$ is the sprung mass, $m_{u f}$ the unsprung mass at the front including the front wheels and axle, and $m_{u r}$ the unsprung mass at the rear with the rear wheels and axle. The symbols of the yaw-roll model are found in Table 2.

In the vehicle modelling, the differential equations of motion of the yaw-roll dynamics of the single unit vehicle, i.e. the lateral dynamics, the yaw moment, the roll moment of the sprung mass, the roll moment of the front and the rear unsprung masses, are formalized 

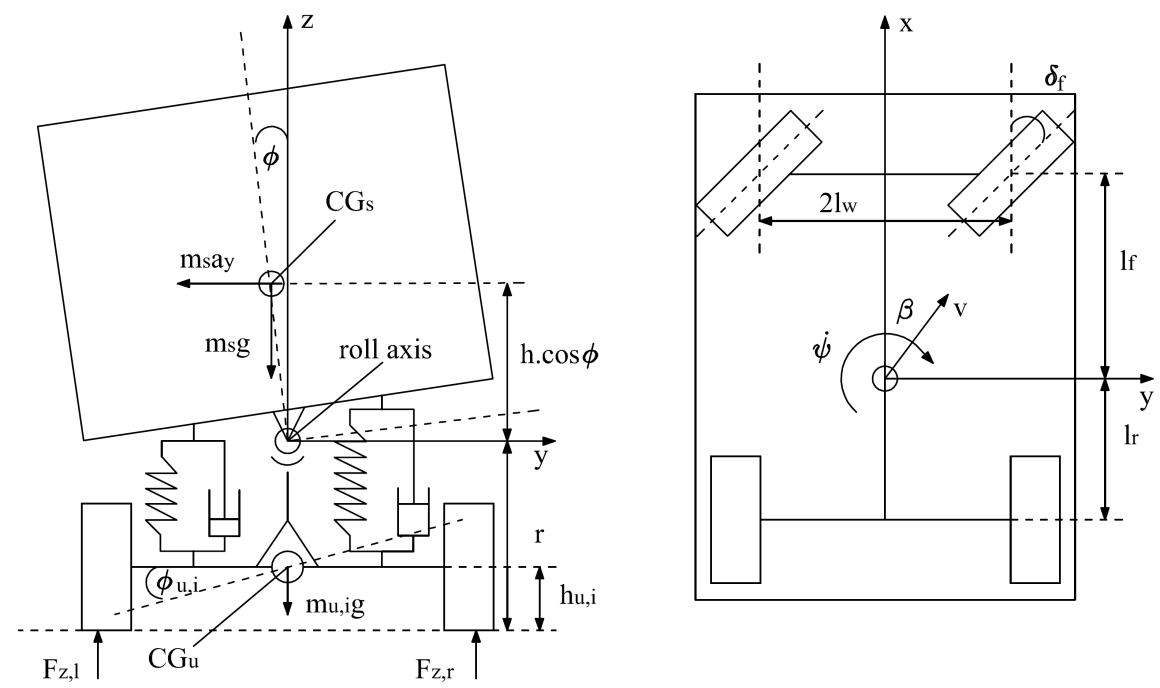

Figure 2. Yaw-Roll model of single unit heavy vehicle [4].

Table 2. Symbols of the yaw-roll model [4].

\begin{tabular}{llll}
\hline Symbols & Description & Symbols & Description \\
\hline$m_{s}$ & Sprung mass & $T_{f}$ & Control torque at the front axle \\
$m_{u, f}$ & Unsprung mass at the front axle & $T_{r}$ & Control torque at the rear axle \\
$m_{u, r}$ & Unsprung mass at the rear axle & $C_{f}$ & Tyre cornering stiffness at the front axle \\
$m$ & The total vehicle mass & $C_{r}$ & Tyre cornering stiffness at the rear axle \\
$v$ & Forward velocity & $k_{f}$ & Suspension roll stiffness at the front axle \\
$v_{w i}$ & Components of the forward velocity & $k_{r}$ & Suspension roll stiffness at the rear axle \\
$h$ & Height of CG of sprung mass from roll axis & $b_{f}$ & Suspension roll damping at the front axle \\
$h_{u}$ & Height of CG of unsprung mass from ground & $b_{r}$ & Suspension roll damping at the rear axle \\
$r$ & Height of roll axis from ground & $k_{t f}$ & Tyre roll stiffness at the front axle \\
$a_{y}$ & Lateral acceleration & $k_{t r}$ & Tyre roll stiffness at the rear axle \\
$\beta$ & Side-slip angle at center of mass & $I_{x x}$ & Roll moment of inertia of sprung mass \\
$\psi$ & Heading angle & $I_{x z}$ & Yaw-roll product of inertia of sprung mass \\
$\dot{\psi}$ & Yaw rate & $I_{z z}$ & Yaw moment of inertia of sprung mass \\
$\alpha$ & Side slip angle & $l_{f}$ & Length of the front axle from the CG \\
$\phi$ & Sprung mass roll angle & $l_{r}$ & Length of the rear axle from the CG \\
$\phi_{u, f}$ & Unsprung mass roll angle at the front axle & $l_{w}$ & Half of the vehicle width \\
$\phi_{u, r}$ & Unsprung mass roll angle at the rear axle & $\mu$ & Road adhesion coefficient \\
$\delta_{f}$ & Steering angle & $\mathrm{g}$ & Gravity of Earth \\
\hline
\end{tabular}

in the equations (10):

$$
\left\{\begin{array}{l}
m v(\dot{\beta}+\dot{\psi})-m_{s} h \ddot{\phi}=F_{y f}+F_{y r} \\
-I_{x z} \ddot{\phi}+I_{z z} \ddot{\psi}=F_{y f} l_{f}-F_{y r} l_{r} \\
\left(I_{x x}+m_{s} h^{2}\right) \ddot{\phi}-I_{x z} \ddot{\psi}=m_{s} g h \phi+m_{s} v h(\dot{\beta}+\dot{\psi})-k_{f}\left(\phi-\phi_{u f}\right) \\
\quad-b_{f}\left(\dot{\phi}-\dot{\phi}_{u f}\right)+M_{A R f}+T_{f}-k_{r}\left(\phi-\phi_{u r}\right)-b_{r}\left(\dot{\phi}-\dot{\phi}_{u r}\right)+M_{A R r}+T_{r} \\
-r F_{y f}=m_{u f} v\left(r-h_{u f}\right)(\dot{\beta}+\dot{\psi})+m_{u f} g h_{u f} \cdot \phi_{u f}-k_{t f} \phi_{u f} \\
\quad+k_{f}\left(\phi-\phi_{u f}\right)+b_{f}\left(\dot{\phi}-\dot{\phi}_{u f}\right)+M_{A R f}+T_{f} \\
-r F_{y r}=m_{u r} v\left(r-h_{u r}\right)(\dot{\beta}+\dot{\psi})-m_{u r} g h_{u r} \phi_{u r}-k_{t r} \phi_{u r} \\
\quad+k_{r}\left(\phi-\phi_{u r}\right)+b_{r}\left(\dot{\phi}-\dot{\phi}_{u r}\right)+M_{A R r}+T_{r}
\end{array}\right.
$$

The lateral tyre forces $F_{y ; i}$ in the direction of velocity at the wheel ground contact points 
are modelled by using linear stiffness coefficients as:

$$
\left\{\begin{array}{l}
F_{y f}=\mu C_{f} \alpha_{f} \\
F_{y r}=\mu C_{r} \alpha_{r}
\end{array}\right.
$$

with the tyre side slip angles:

$$
\left\{\begin{array}{l}
\alpha_{f}=-\beta+\delta_{f}-\frac{l_{f} \dot{\psi}}{v} \\
\alpha_{r}=-\beta+\frac{l_{r} \dot{\psi}}{v}
\end{array}\right.
$$

The moment of passive anti-roll bar impacts the unsprung and sprung masses at the front and rear axles as follows, see [20]:

$$
\left\{\begin{array}{l}
M_{A R f}=4 k_{A O f} \frac{t_{A} t_{B}}{c^{2}} \phi-4 k_{A O f} \frac{t_{A}^{2}}{c^{2}} \phi_{u f} \\
M_{A R r}=4 k_{A O r} \frac{t_{A} t_{B}}{c^{2}} \phi-4 k_{A O r} \frac{t_{A}^{2}}{c^{2}} \phi_{u r}
\end{array}\right.
$$

where $k_{A O f}, k_{A O r}$ are respectively the torsional stiffnesses of the anti-roll bar at the front and rear axles, $t_{A}$ is half the distance of the two suspensions, $t_{B}$ is half the distance of the chassis, $c$ is the length of the anti-roll bars' arm.

\subsection{Integrated model of the single unit heavy vehicle}

\subsubsection{Full integrated model of the single unit heavy vehicle}

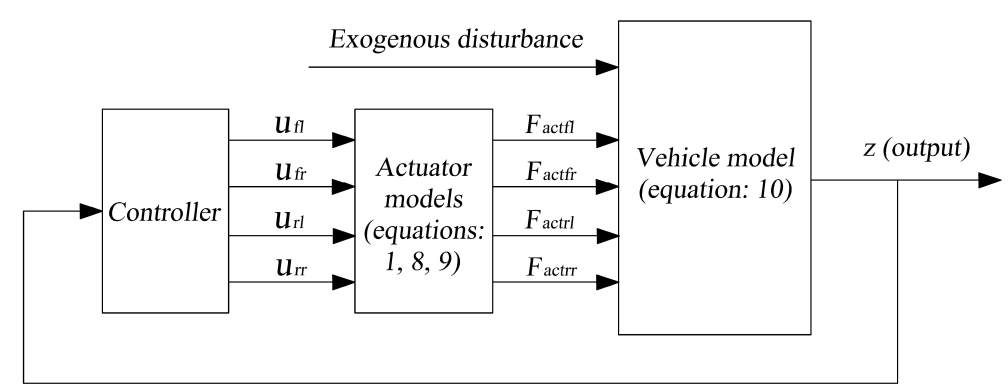

Figure 3. Diagram of the full integrated model of the single unit heavy vehicle using active anti-roll bar.

Figure 3 shows the full integrated model of the single unit heavy vehicle using active anti-roll bar. This model includes a linear single unit heavy vehicle yaw-roll model with the differential equations of motion given in (10) and four electronic servo-valve hydraulic actuators (two at the front axle and two at the rear axle) with the differential equations of motion are given in (1), (8), (9). The controller receives the informations from the output $(z)$ and defines the input currents $\left(u_{f l}, u_{f r}, u_{r l}, u_{r r}\right)$, where $u_{f l}$ and $u_{f r}$ are respectively the input currents of the electronic servo-valves on the left and on the right at the front axle, $u_{r l}$ and $u_{r r}$ at the rear axle. The forces $\left(F_{a c t f l}, F_{a c t f r}, F_{a c t r l}, F_{a c t r r}\right)$ of the hydraulic actuators are applied to the vehicle model, where $F_{\text {actfl }}$ and $F_{\text {actfr }}$ are respectively the forces of the hydraulic actuators on the left and on the right at the front axle, $F_{a c t r l}$ and $F_{a c t r r}$ at the rear axle. Therefore the torque generated by the active anti-roll bar system 
at the front axle is determined by:

$$
T_{f}=-l_{\text {act }} F_{a c t f l}+l_{\text {act }} F_{a c t f r}
$$

and the torque generated by the active anti-roll bar system at the rear axle is:

$$
T_{r}=-l_{a c t} F_{a c t r l}+l_{a c t} F_{a c t r r}
$$

where $l_{\text {act }}$ is half the distance of the two actuators.

In the rest of the paper, it is assumed that, at each axle, the right and left electronic servo-valve hydraulic actuators are identical and symmetrically mounted. Therefore, at each axle, the characteristics of the two electronic servo-valve hydraulic actuators do have the same magnitude and the opposite direction as follows:

- Forces:

$$
F_{\text {actfl }}=-F_{\text {actfr }} \quad \text { and } \quad F_{\text {actrl }}=-F_{\text {actrr }}
$$

- Load flows:

$$
Q_{L f l}=-Q_{L f r} \quad \text { and } \quad Q_{L r l}=-Q_{L r r}
$$

- Spool valve displacements:

$$
X_{v f l}=-X_{v f r} \quad \text { and } \quad X_{v r l}=-X_{v r r}
$$

- Input currents:

$$
u_{f l}=-u_{f r} \quad \text { and } \quad u_{r l}=-u_{r r}
$$

where $Q_{L f l}$ and $Q_{L f r}$ are respectively the load flows of the electronic servo-valves on the left and on the right at the front axle, $Q_{L r l}$ and $Q_{L r r}$ at the rear axle. $X_{v f l}$ and $X_{v f r}$ are respectively the spool valve displacements of the electronic servo-valves on the left and on the right at the front axle, $X_{v r l}$ and $X_{v r r}$ at the rear axle.

Since the forces of the two electronic servo-valve hydraulic actuators do have the same magnitude and the opposite direction, the active anti-roll bar system does not have an influence on the vertical motion of heavy vehicle.

\subsubsection{Control-oriented integrated model of the single unit heavy vehicle}

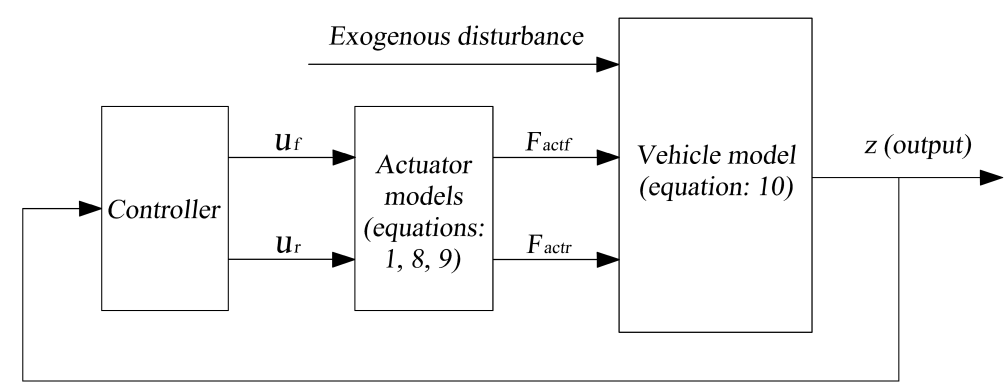

Figure 4. Diagram of control-oriented integrated model of the single unit heavy vehicle using active anti-roll bar. 
The torques generated by the active anti-roll bar system at the two axles are determined in equations (14)-(15); furthermore the forces, as well as other characteristics of the electronic servo-valve hydraulic actuators at each axle, do have the same magnitude and the opposite direction, therefore we can consider that the torque generated by the active anti-roll bar system at each axle is twice the torque generated by one electronic servovalve hydraulic actuator. Using the hypothesis concerning the model symmetry given above, a model reduction is detailed in the sequel.

Figure 4 shows the diagram of control-oriented integrated model of the single unit heavy vehicle using active anti-roll bar, where $u_{f}, u_{r}$ and $F_{\text {actf }}, F_{\text {actr }}$ are respectively the input currents and the forces of one of the two electronic servo-valve hydraulic actuators at the front and rear axles. In this study, the characteristics of the electronic servo-valve hydraulic actuators on the right at the front, and on the right at the rear axle will be used. From Figure 3 and Figure 4, the mathematical relationships between the forces as well as the input currents at each axle are given as:

$$
\left\{\begin{array}{l}
F_{a c t f l}=-F_{a c t f r} \\
F_{a c t r l}=-F_{a c t r r} \\
F_{a c t f}=F_{a c t f r} \\
F_{a c t r}=F_{a c t r r} \\
u_{f}=u_{f r} \\
u_{r}=u_{r r}
\end{array}\right.
$$

From equations (14), (15) and (20), the torque generated by the active anti-roll bar system at the front axle is now determined by:

$$
T_{f}=2 l_{a c t} F_{a c t f}=2 l_{a c t} A_{p} \Delta_{P f}
$$

and the torque generated by the active anti-roll bar system at the rear axle is:

$$
T_{r}=2 l_{\text {act }} F_{\text {actr }}=2 l_{\text {act }} A_{p} \Delta_{P r}
$$

where $\Delta_{P f}$ and $\Delta_{P r}$ are respectively the difference of pressure of the hydraulic actuator at the front and rear axles. They are given by the state equation (24).

The displacements $\left(y_{a f, r}\right)$ of the piston of the hydraulic actuators at each axle are approximately calculated as follows [1]:

$$
y_{a f, r}=l_{a c t}\left(\phi-\phi_{u f, r}\right)
$$

From equations (1), (8), (9) and (23), the equations of these electronic servo-valve actuators are given by:

$$
\left\{\begin{array}{l}
\frac{V_{t}}{4 \beta_{e}} \dot{\Delta}_{P f}+\left(K_{P}+C_{t p}\right) \Delta_{P f}-K_{x} X_{v f}+A_{p} l_{a c t} \dot{\phi}-A_{p} l_{a c t} \dot{\phi}_{u f}=0 \\
\dot{X}_{v f}+\frac{1}{\tau} X_{v f}-\frac{K_{v}}{\tau} u_{f}=0 \\
\frac{V_{t}}{4 \beta_{e}} \dot{\Delta}_{P r}+\left(K_{P}+C_{t p}\right) \Delta_{P r}-K_{x} X_{v r}+A_{p} l_{a c t} \dot{\phi}-A_{p} l_{a c t} \dot{\phi}_{u r}=0 \\
\dot{X}_{v r}+\frac{1}{\tau} X_{v r}-\frac{K_{v}}{\tau} u_{r}=0
\end{array}\right.
$$


Defining the state vector:

$$
x=\left[\beta \dot{\psi} \phi \dot{\phi} \phi_{u f} \phi_{u r} \Delta_{P f} X_{v f} \Delta_{P r} X_{v r}\right]^{T}
$$

where $X_{v f}$ and $X_{v r}$ are the spool valve displacements at the front and rear axles, respectively, the motion differential equations (10)-(24) can be rewritten in the LTI state-space representation as:

$$
\left\{\begin{array}{l}
\dot{x}=A \cdot x+B_{1} \cdot w+B_{2} \cdot u \\
z=C \cdot x+D_{1} \cdot w+D_{2} \cdot u
\end{array}\right.
$$

where $A, B_{1}, B_{2}, C, D_{1}, D_{2}$ are model matrices of appropriate dimensions. The matrices $A, B_{1}$ and $B_{2}$ are shown in Appendix.

The exogenous disturbance is:

$$
w=\left[\delta_{f}\right]^{T}
$$

and the control inputs:

$$
u=\left[\begin{array}{ll}
u_{f} & u_{r}
\end{array}\right]^{T}
$$

The variables of interest include:

(1) The characteristics of the single unit heavy vehicle: $\beta, \dot{\psi}, \phi, \dot{\phi}, \phi_{u f}, \phi_{u r}, \phi-\phi_{u f}, \phi-\phi_{u r}$

(2) The characteristics of the actuators: $Q_{L f}, Q_{L r}, F_{a c t f}, F_{a c t r}, X_{v f}, X_{v r}, u_{f}, u_{r}$

(3) The roll stability: $R_{f}, R_{r}$

where $R_{f}$ and $R_{r}$ are respectively the normalized load transfer at the front and rear axles, defined as follows [4], [8]:

$$
R_{f}=\frac{\Delta F_{z f}}{F_{z f}}, \quad R_{r}=\frac{\Delta F_{z r}}{F_{z r}}
$$

where $F_{z f}$ is the total axle load at the front axle and $F_{z r}$ at the rear axle. $\Delta F_{z f}$ and $\Delta F_{z r}$ are respectively the lateral load transfers at the front and rear axles, which can be given by:

$$
\Delta F_{z f}=\frac{k_{u f} \phi_{u f}}{l_{w}}, \quad \Delta F_{z r}=\frac{k_{u r} \phi_{u r}}{l_{w}}
$$

where $k_{u f}$ and $k_{u r}$ are the stiffness of the tyres, $\phi_{u f}$ and $\phi_{u r}$ are the roll angles of the unsprung masses at the front and rear axles, $l_{w}$ the half of vehicle's width.

\section{ACTIVE ANTI-ROLL BAR OPTIMAL CONTROL}

The objective of the active anti-roll bar control system is to maximize the roll stability of the heavy vehicle. An imminent rollover can be detected if the calculated normalized load transfers $R_{f, r}$ defined in equation (26) reach 1 (or -1 ). Therefore, the performance characteristics which are of most interest when designing the active anti-roll bar, are the 
normalized load transfers $R_{f, r}$ that the controller should minimize. While attempting to minimize the normalized load transfer, it is also necessary to constrain the roll angles between the sprung and unsprung masses $\left(\phi-\phi_{u f, r}\right)$ within the limits of the travel of suspension $(7 \div 8 \mathrm{deg})$ [4]. Such control objectives are tackled using the $L Q R$ approach briefly summarized below.

\subsection{Background on Linear Quadratic Regulator (LQR)}

The linear time-invariant (LTI) model is described by equation (25). For controller design, it is assumed that all the states are available from measurements or can be estimated. Then, let us consider the state feedback control law:

$$
u=-K x
$$

where $K$ is the state feedback gain matrix. The optimization procedure consists in determining the control input $u$ which minimizes some performance index $J$. This index includes the performance characteristic requirement as well as the controller input limitations, usually expressed by:

$$
J=\int_{0}^{\infty}\left(x^{\mathrm{T}} \mathcal{Q} x+u^{\mathrm{T}} \mathcal{R} u\right) \mathrm{d} t
$$

where $\mathcal{Q}$ and $\mathcal{R}$ are positive definite weighting matrices. To obtain a solution for the optimal controller (28), the LTI system must be stabilizable, which is true for the system (25).

From the linear optimal control theory [21], the gain $K$ minimizing (29) has the following form:

$$
K=\mathcal{R}^{-1} B^{T} \mathcal{P}
$$

where the matrix $\mathcal{P}$ is the solution of the Algebraic Riccati Equation (ARE):

$$
A \mathcal{P}+A^{T} \mathcal{P}-\mathcal{P} B \mathcal{R}^{-1} B^{T} \mathcal{P}+\mathcal{Q}=0
$$

The optimal closed-loop system is obtained from equations (25), (28) and (30) as follows:

$$
\dot{x}=\left(A-B_{2} K\right) x+B_{1} w
$$

\subsection{Active anti-roll bar $L Q R$ control}

The main objective is here to maximize the roll stability. The sprung mass roll angle $(\phi)$, the roll angle of suspensions $\left(\phi-\phi_{u f, r}\right)$ and the normalized load transfers $\left(R_{f, r}\right)$ are variables directly affecting the roll stability of the vehicle, so they are to be minimized. Besides, it is important to handle the input current limitations $\left(u_{f}, u_{r}\right)$ of the electronic servo-valve hydraulic actuators. For these reasons, the performance index $J$ is selected as follows: 


$$
\begin{aligned}
J=\int_{0}^{\infty} & \left(\rho_{1} \phi^{2}+\rho_{2} R_{f}^{2}+\rho_{3} R_{r}^{2}+\rho_{4}\left(\phi-\phi_{u f}\right)^{2}\right. \\
& \left.+\rho_{5}\left(\phi-\phi_{u r}\right)^{2}+R_{u f} u_{f}^{2}+R_{u r} u_{r}{ }^{2}\right) \mathrm{dt}
\end{aligned}
$$

where $\rho_{1}, \rho_{2}, \rho_{3}, \rho_{4}, \rho_{5}, R_{u f}$ and $R_{u r}$ are the weighting parameters of $J$.

According to the choice of these parameters, (33) allows to handle a large set of different criteria focusing on anti-roll bar performances and/or on the limitation of actuator consumptions.

In this paper, to assess the quality of the active anti-roll bar control system, three controllers have been designed and compared, using three different sets of weighting parameters:

- First control design ( $L Q R_{1}$ - Nominal): Roll stability and controller input current limitations are considered. The weighting parameters values are chosen as:

$$
\rho_{1}=\rho_{2}=\rho_{3}=\rho_{4}=\rho_{5}=1 ; \quad R_{u f}=R_{u r}=1
$$

With this controller, the role of the roll stability and the input current limitations to be considered is balanced.

- Second control design ( $L Q R_{2}$ - Normalized load transfer oriented): Roll stability is taken into account and the normalized load transfers $\left(R_{f}, R_{r}\right)$ are the most important objectives, while keeping the controller input current limitations. The weighting parameters values are chosen as:

$$
\rho_{1}=\rho_{4}=\rho_{5}=R_{u f}=R_{u r}=1 ; \quad \rho_{2}=\rho_{3}=10,50,100,200,500,1000,10000
$$

where the weighting parameters values $\rho_{2}, \rho_{3}$ are changed from 10 to 10000; this selection is used to consider the roll stability, the behaviors of the heavy vehicle as well as of the electronic servo-valve hydraulic actuators when the normalized load transfers are more and more penalized.

- Third control design ( $L Q R_{3}$ - Input limitation oriented): Controller input current limitations $\left(u_{f}, u_{r}\right)$ are more taken into account, while keeping the roll stability objective. The weighting parameters values are chosen as:

$$
\rho_{1}=\rho_{2}=\rho_{3}=\rho_{4}=\rho_{5}=1 ; \quad R_{u f}=R_{u r}=10,50,100,200,500,1000,10000
$$

In this case, the weighting parameters values $R_{u f}, R_{u r}$ are changed from 10 to 10000 , the objective is to consider the roll stability, the behaviors of the heavy vehicle as well as the electronic servo-valve hydraulic actuator with harder input current limitations.

Remark: Of course, other controllers could be designed using (33) with other choices of the weighting parameters, according to specifications.

\section{SIMULATION RESULTS ANALYSIS}

In this section, the simulation results of the single unit heavy vehicle using the four electronic servo-valve hydraulic actuators with a full-state feedback controller are shown in both frequency and time domains. The parameters values of the electronic servo-valve 
Table 3. Parameters of the yaw-roll model [4], [20].

\begin{tabular}{ll|ll|ll}
\hline Parameter & Value & Parameter & Value & Parameter & Value \\
\hline$m_{s}$ & $12487 \mathrm{~kg}$ & $b_{f}$ & $100 \frac{\mathrm{kN}}{r q d}$ & $I_{x x}$ & $24201 \mathrm{kgm}^{2}$ \\
$m_{u, f}$ & $706 \mathrm{~kg}$ & $b_{r}$ & $100 \frac{\mathrm{kN}}{r a d}$ & $I_{x z}$ & $4200 \mathrm{kgm}^{2}$ \\
$m_{u, r}$ & $1000 \mathrm{~kg}$ & $k_{t f}$ & $2060 \frac{\mathrm{kNm}}{r a d}$ & $I_{z z}$ & $34917 \mathrm{kgm}^{2}$ \\
$m$ & $14193 \mathrm{~kg}$ & $k_{t r}$ & $3337 \frac{\mathrm{kNm}}{\mathrm{rad}}$ & $l_{w}$ & $0.93 \mathrm{~m}$ \\
$h$ & $1.15 \mathrm{~m}$ & $k_{f}$ & $380 \frac{\mathrm{kNm}}{r a d}$ & $l_{f}$ & $1.95 \mathrm{~m}$ \\
$h_{u, i}$ & $0.53 \mathrm{~m}$ & $k_{r}$ & $684 \frac{\mathrm{kNm}}{\mathrm{rad}}$ & $l_{r}$ & $1.54 \mathrm{~m}$ \\
$C_{f}$ & $582 \frac{\mathrm{kN}}{\mathrm{rad}}$ & $k_{A O f}$ & $10730 \frac{\mathrm{Nm}}{\mathrm{rad}}$ & $r$ & $0.83 \mathrm{~m}$ \\
$C_{r}$ & $783 \frac{\mathrm{kN}}{\mathrm{rad}}$ & $k_{\text {AOr }}$ & $15480 \frac{\mathrm{Nm}}{\mathrm{rad}}$ & $\mu$ & 1 \\
\hline
\end{tabular}

hydraulic actuators and of the yaw-roll model are those given in tables 1 and 3 . The forward velocity is constant $(70 \mathrm{~km} / \mathrm{h})$.

\subsection{Analysis in the frequency domain}

Various closed loop transfer functions of the integrated model of the single unit heavy vehicle are shown in this section. To assess the effect of the weighting parameters $\rho_{2}$ and $\rho_{3}$ of the $L Q R_{2}$ design and the weighting parameters $R_{u f}$ and $R_{u r}$ of the $L Q R_{3}$ design, two cases are considered and detailed:

(1) First case: the transfer functions are shown for the passive anti-roll bar, the $L Q R_{1}$ design and the $L Q R_{2}$ design,

(2) Second case: the transfer functions are shown for the passive anti-roll bar, the $L Q R_{1}$ design and the $L Q R_{3}$ design.

They are detailed in the sequel.

4.1.1. First case: effect of $\rho_{2}$ and $\rho_{3}$ on the transfer functions $\frac{R_{f, r}}{\delta_{f}}$ and $\frac{u_{f, r}}{\delta_{f}}$
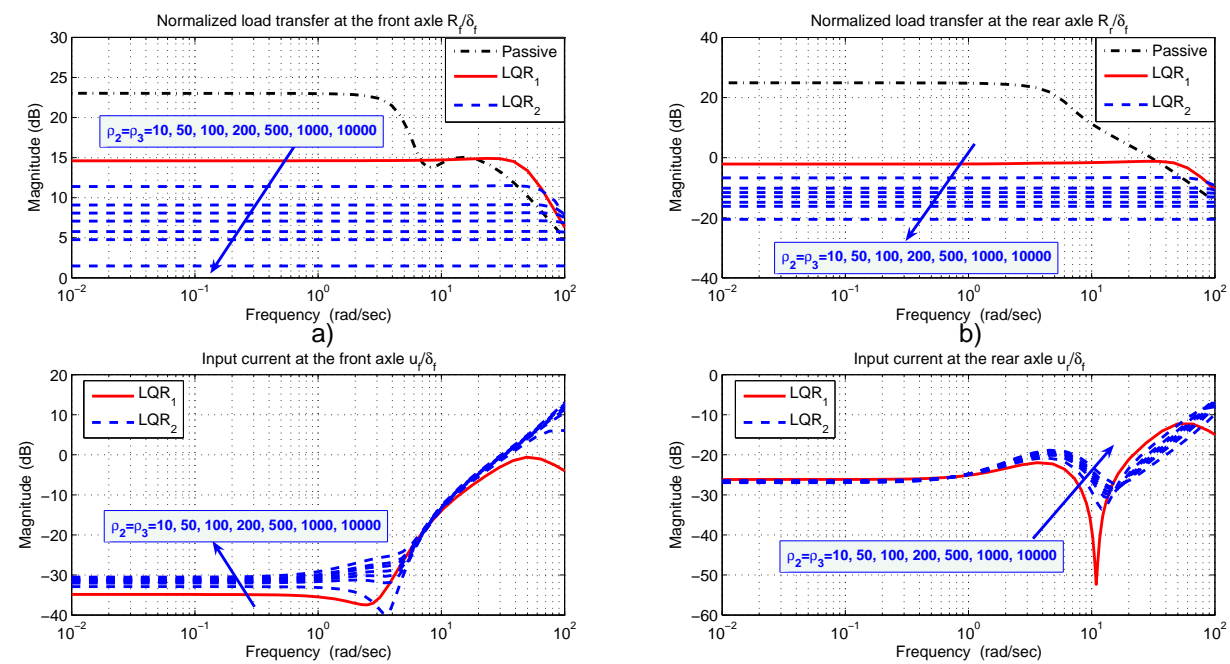

c)

d)

Figure 5. Case 1, transfer functions magnitude of $(\mathrm{a}, \mathrm{b})$ normalized load transfers $\left(\frac{R_{f, r}}{\delta_{f}}\right)$ and $(\mathrm{c}, \mathrm{d})$ input currents $\left(\frac{u_{f, r}}{\delta_{f}}\right)$ at the axles. 
The main objective of the active anti-roll bar system is to reduce the normalized load transfer at each axle. Figures $5 a, b$ show the transfer function of the normalized load transfers at the front axle $\left(\frac{R_{f}}{\delta_{f}}\right)$ and at the rear axle $\left(\frac{R_{r}}{\delta_{f}}\right)$, respectively. As shown in Table 4 , both $L Q R_{1}$ and $L Q R_{2}$ designs allow to reduce the normalized load transfers (at the two axles) compared with the passive anti-roll bar case. When $\rho_{2}$ and $\rho_{3}$ increase, the transfer function's gains of the normalized load transfers decrease in the case of the $L Q R_{2}$ design.

The reduction of normalized load transfers at the axles is due to the active anti-roll bar system. Indeed, when the vehicle rolls into the corner, unlike in the passive anti-roll bar case, the active one generates a stabilizing lateral displacement moment, which balances the destabilizing overturning moment caused by lateral acceleration [4], [5].

Table 4. Reduction of the magnitude of transfer functions compared with the passive case.

\begin{tabular}{lc|c}
\hline Transfer functions & $L Q R_{1}$ & $L Q R_{2}$ \\
\hline$\frac{R_{f}}{\delta_{f}}$ & $8 \mathrm{~dB}[0,6 \mathrm{rad} / \mathrm{s}]$ & $11 \mathrm{~dB}\left(\rho_{2}=\rho_{3}=10\right), 21 \mathrm{~dB}\left(\rho_{2}=\rho_{3}=10000\right)[0,40 \mathrm{rad} / \mathrm{s}]$ \\
$\frac{R_{r}}{\delta_{f}}$ & $27 \mathrm{~dB}[0,30 \mathrm{rad} / \mathrm{s}]$ & $30 \mathrm{~dB}\left(\rho_{2}=\rho_{3}=10\right), 43 \mathrm{~dB}\left(\rho_{2}=\rho_{3}=10000\right)[0,50 \mathrm{rad} / \mathrm{s}]$ \\
\hline
\end{tabular}

Figures $5 c, d$ show the transfer functions gains of the input currents at the front $\left(\frac{u_{f}}{\delta_{f}}\right)$ and rear axles $\left(\frac{u_{r}}{\delta_{f}}\right)$, respectively. When $\rho_{2}$ and $\rho_{3}$ increase, the controller input currents $\left(u_{f, r}\right)$ increase. This indicates that when the weighting parameters $\rho_{2}, \rho_{3}$ increase, the $L Q R_{2}$ design requires more input current (i.e. energy) than does the $L Q R_{1}$ design.

The simulation results in the frequency domain have shown that the $L Q R_{2}$ design improves the roll stability of single unit heavy vehicle when $\rho_{2}$ and $\rho_{3}$ increase. However, it also increases the controller input current. This consistently fulfils the objective of the designed controllers. But as current is limited to $20 \mathrm{~mA}$ [18], $\rho_{2}$ and $\rho_{3}$ should not be increased too much to stay within the current constraints.

\subsubsection{Second case: effect of $R_{u f}$ and $R_{u r}$ on the transfer functions $\frac{R_{f, r}}{\delta_{f}}$ and $\frac{u_{f, r}}{\delta_{f}}$}

The $L Q R_{1}$ design is designed to enhance roll stability while considering also the controller input current limitations $\left(u_{f, r}\right)$. Conversely, the $L Q R_{3}$ design considers mainly the controller input current limitations and pays less attention to the roll stability. Figures $6 a, b$ show the transfer functions gains of the normalized load transfer at the front axle $\left(\frac{R_{f}}{\delta_{f}}\right)$ and rear axle $\left(\frac{R_{r}}{\delta_{f}}\right)$, respectively. In Table 5 , the reduction of the normalized load transfers (at the two axles) are shown for the $L Q R_{1}$ and $L Q R_{3}$ designs compared with the passive anti-roll bar case. They show that, compared to $L Q R_{1}$, the $L Q R_{3}$ design improves less the roll stability, when $R_{u f}$ and $R_{u r}$ increase from 10 to 10000 .

Table 5. Reduction of the magnitude of transfer functions compared with the passive case.

\begin{tabular}{lc|c}
\hline Transfer functions & $L Q R_{1}$ & $L Q R_{3}$ \\
\hline$\frac{R_{f}}{\delta_{f}}$ & $8 \mathrm{~dB}[0,6 \mathrm{rad} / \mathrm{s}]$ & $5.5 \mathrm{~dB}\left(R_{u f}=R_{u r}=10\right), 3.5 \mathrm{~dB}\left(R_{u f}=R_{u r}=10000\right)[0,5 \mathrm{rad} / \mathrm{s}]$ \\
$\frac{R_{r}}{\delta_{f}}$ & $27 \mathrm{~dB}[0,30 \mathrm{rad} / \mathrm{s}]$ & $21 \mathrm{~dB}\left(R_{u f}=R_{u r}=10\right), 4 \mathrm{~dB}\left(R_{u f}=R_{u r}=10000\right)[0,10 \mathrm{rad} / \mathrm{s}]$ \\
\hline
\end{tabular}

Figures $6 c, d$ show the transfer functions gains of the input currents at the front $\left(\frac{u_{f}}{\delta_{f}}\right)$ and rear axles $\left(\frac{u_{r}}{\delta_{f}}\right)$, respectively. When $R_{u f}$ and $R_{u r}$ increase, the controller input currents $\left(u_{f, r}\right)$ decrease. This indicates that when $R_{u f}$ and $R_{u r}$ increase, the $L Q R_{3}$ design requires less energy than does the $L Q R_{1}$ design. 

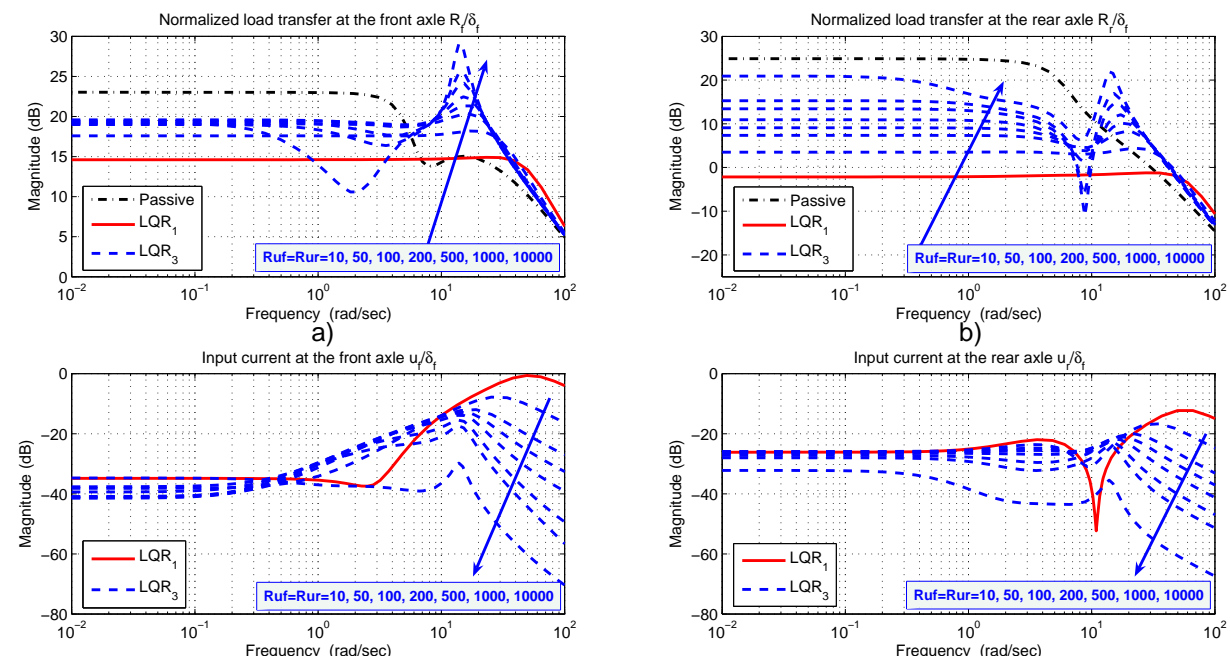

c)

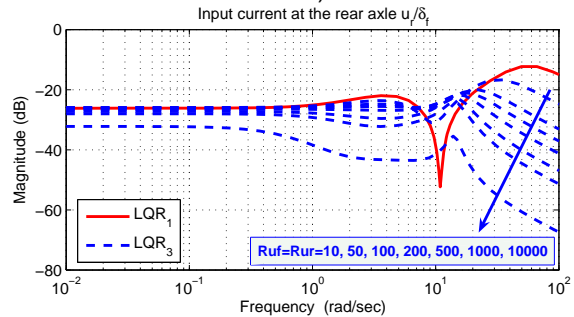

d)

Figure 6. Case 2, transfer functions magnitude of (a, b) normalized load transfers $\left(\frac{R_{f, r}}{\delta_{f}}\right)$ and (c, d) input currents $\left(\frac{u_{f, r}}{\delta_{f}}\right)$ at the axles.

From Figure 6, we can see that the $L Q R_{3}$ design does not improve the roll stability of single unit heavy vehicle when $R_{u f}$ and $R_{u r}$ increase. As the main objective of the active anti-roll bar system is to enhance the roll stability, $R_{u f}$ and $R_{u r}$ cannot be increased too much.

The results above indicate that the roll stability and the energy consumption are conflicting objectives. The objective of the active anti-roll bar on heavy vehicles is to maximize roll stability to prevent rollover in dangerous situations. However, such a performance objective must be balanced with the energy consumption of the anti-roll bar system, which is not a trivial task.

The selection of the performance index $J$, as well as the weighting parameters $\left(\rho_{1}, \rho_{2}\right.$, $\rho_{3}, \rho_{4}, \rho_{5}, R_{u f}$ and $R_{u r}$ ) in the equation (33) depend on the design objective. However, they must be chosen to satisfy simultaneously the three targets:

- The roll stability, which is expressed by the limits of the normalized load transfers at all axles in the range $[-1,1]$, in the frequency range up to over $4 \mathrm{rad} / \mathrm{s}[7]$.

- The saturation of the actuators, which is expressed by the maximum absolute value of the spool valve displacement less than $4.85 \times 10^{-4} \mathrm{~m}$ [18], of the input current less than $20 \mathrm{~mA}$ [18], of the load flow less than $2.2 \times 10^{-3} \mathrm{~m}^{3} / \mathrm{s}$ [7], and of the forces less than $120 \mathrm{kN}[7]$.

- The limits of the suspension travel, which are expressed by the roll angles between the sprung and unsprung masses $\left(\phi-\phi_{u f, r}\right)$ less than $[7 \div 8]$ deg [4].

\subsection{Simulation results in time domain}

In this section, some results in time domain are shown for four different situations: passive anti-roll bar, $L Q R_{1}$ controller (Nominal), $L Q R_{2}$ controller $\left(\rho_{2}=\rho_{3}=100\right.$, Normalized load transfer oriented) and $L Q R_{3}$ controller $\left(R_{u f}=R_{u r}=100\right.$, Input limitation oriented). The vehicle manoeuvre is a double lane change which is often used to avoid an obstacle in an emergency. The manoeuvre has a $2.5 \mathrm{~m}$ path deviation over $100 \mathrm{~m}$. The steering angle $\delta_{f}$ is shown in Figure 7 . 


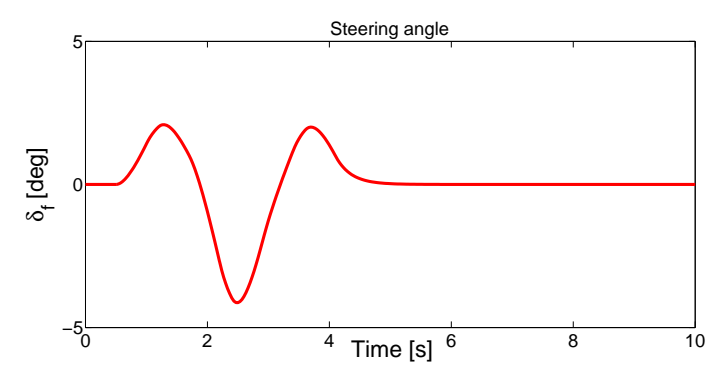

Figure 7. Time responses of steering angle $\delta_{f}[4]$.

\subsubsection{Performance criteria}

To evaluate the efficiency of the controllers, two criteria are considered:

- The maximum of the absolute value of the signals. This indicator is very important for the normalized load transfers $R_{f, r}$, because if $R_{f, r}$ takes on the value \pm 1 , then the inner wheel in the bend lifts off.

- The Root Mean Square (RMS) of the signals are defined as:

$$
R M S(y)=\sqrt{\frac{1}{T} \int_{0}^{T} \mathrm{y}^{2}(\mathrm{t}) \mathrm{dt}}
$$

\subsubsection{Analysis of the roll stability and the electronic servo-valve hydraulic actuator}


c)

d)

Figure 8. Time responses of (a, b) normalized load transfers and (c, d) input currents at the axles.

In Figure 8, the time responses for the $L Q R_{1}$ controller (continuous line), the $L Q R_{2}$ controller (dashed line), the $L Q R_{3}$ controller (dashed-dot line) and the passive anti-roll bar (dashed-dot asterisk line) are shown.

Figures $8 a, b$ show the normalized load transfers at the front and rear axles, respectively. Notice that, in the passive anti-roll bar case, the value of the normalized load transfer at the rear axle $\left(R_{r}\right)$ at 2.8 seconds exceeds -1 so that the inner wheels lifts off (but not at the front axle). For the three $L Q R$ active anti-roll bar controllers, the roll stability is 
achieved because the limits of the normalized load transfers always stay within \pm 1 . In Table 6, the reduction of the peak of the normalized load transfers (at the two axles) are shown for the three $L Q R$ designs compared with the passive anti-roll bar case. This confirms the simulation results in the frequency domain which are shown in Figures $5 a, b$ and $6 a, b$.

Table 6. Reduction of the peak of the normalized load transfers compared with the passive case $(100 \%)$.

\begin{tabular}{ll|l|l}
\hline Normalized load transfers & $L Q R_{1}$ & $L Q R_{2}$ & $L Q R_{3}$ \\
\hline$R_{f}$ & $70 \%$ & $83 \%$ & $37 \%$ \\
$R_{r}$ & $96 \%$ & $98 \%$ & $89 \%$ \\
\hline
\end{tabular}

To assess the roll stability and the energy consumption of the actuators using the three active anti-roll bar controllers, the simulation results are summarized in Figure 9.

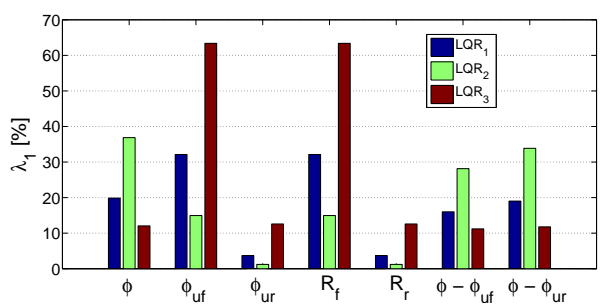

(a)

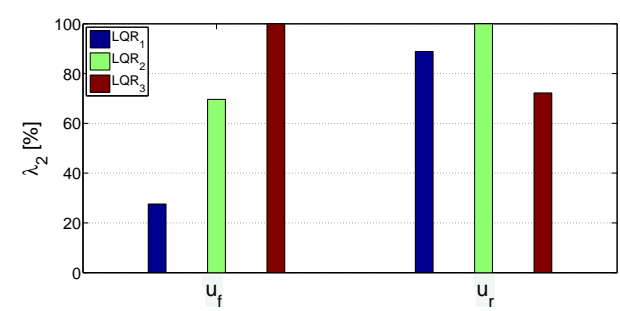

(b)

Figure 9. RMS of the signal's reduction: $\lambda_{1}(\mathrm{a}), \lambda_{2}$ (b)

For the roll stability, we consider the percentage of Root Mean Square (RMS) compared with that of the passive anti-roll bar case $(100 \%)$ as:

$$
\lambda_{1}(.)=\frac{R M S(\text { active })}{R M S(\text { passive })} 100 \%
$$

For the energy consumption of the actuators, the percentage of $R M S$ compares with the maximum $R M S$ of input currents w.r.t. each axle as:

$$
\lambda_{2}(.)=\frac{R M S\left(u_{f, r}\right)}{R M S\left(u_{f, r \max }\right)} 100 \%
$$

Figure $9 a$ shows that for the three $L Q R$ active anti-roll bars, the $R M S$ of the signals have dropped from $63 \%$ to $88 \%$ for the roll angle of sprung mass $(\phi)$, from $37 \%$ to $85 \%$ for the roll angle of the unsprung mass at the front axle $\left(\phi_{u f}\right)$, from $87 \%$ to $98 \%$ for the roll angle of the unsprung mass at the rear axle $\left(\phi_{u r}\right)$, from $37 \%$ to $85 \%$ for the normalized load transfer at the front axle $\left(R_{f}\right)$, from $87 \%$ to $98 \%$ for the normalized load transfer at the rear axle $\left(R_{r}\right)$, from $72 \%$ to $89 \%$ for the roll angle of the suspension at the front axle $\left(\phi-\phi_{u f}\right)$ and from $66 \%$ to $88 \%$ for the roll angle of suspension at the rear axle $\left(\phi-\phi_{u r}\right)$.

Figure $9 b$ indicates that the input currents in case of the $L Q R_{2}$ controller are always higher than those of the $L Q R_{1}$ controller, this consistently fulfils the objective of the designed controllers. Nevertheless in the case of the $L Q R_{3}$ controller, the input current at the front axle is higher than that of the $L Q R_{1}$ and $L Q R_{2}$ controllers, which confirms 
the simulation results in the frequency domain, shown in Figures $5 c$ and $6 c$, since in the time domain, the steering angle is considered at $4 \mathrm{rad} / \mathrm{s}$ in an emergency.

So we can claim that the three active anti-roll bar controllers significantly enhance the roll stability compared with the passive anti-roll bar case. As explained for the choice of the coefficients of the performance index $J$, the simulation results consistently fulfil the objective of the described controllers. This provides the control engineering a generic design method for designing $L Q R$ controllers according to his performance requirements (through the choice of the parameters $\rho_{i}$ )

\subsubsection{Analysis of the handling performance}

Besides improving the roll stability to prevent the rollover, it is important to evaluate the effect of the $L Q R$ active anti-roll bar system on the handling performance of the heavy vehicle using the electronic servo-valve hydraulic actuators. The vehicle stability region is derived from the phase-plane $(\beta-\dot{\beta})$ can be assessed through the Stability Index $(\lambda)$ in equation (37), see [22].

$$
\lambda=|2.49 \dot{\beta}+9.55 \beta|
$$

The heavy vehicle is in the stability region when $\lambda<1$. Figure 10 indicates that in the case of the $L Q R$ active anti-roll bar controllers, the stability index $\lambda$ is always less than that in the case of the passive anti-roll bar, which is important to the driver.

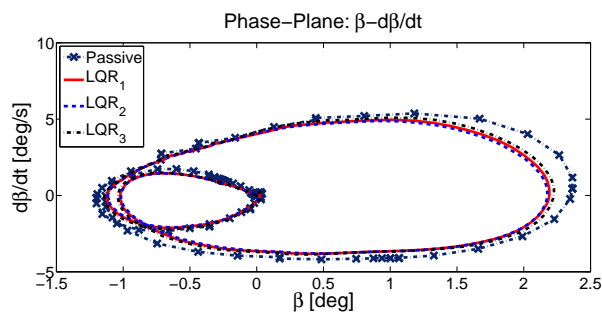

(a)

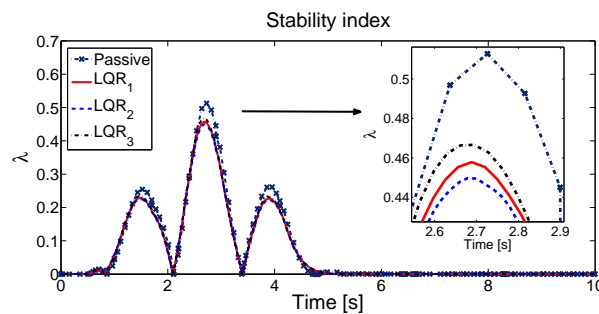

(b)

Figure 10. Phase-Plane $\beta-\dot{\beta}$ (a) and Stability index $\lambda$ (b).

We can conclude that although the $L Q R$ active anti-roll bar controllers focus on the normalized load transfers and input currents, they also improve the handling performance of the heavy vehicle. Of course the $L Q R$ active anti-roll bar controller can improve the handling performance much more if the performance index $J$ in equation (33) takes into account the side-slip angle at the center of mass $(\beta)$, which is related directly to the vehicle stability.

Remark: To evaluate the effect of the three $L Q R$ active anti-roll bar controllers on the roll stability and the electronic servo-valve hydraulic actuator of the integrated model in the frequency and time domains, the signals considered are listed in detail in Table 7.

\section{ANALYSIS OF THE EFFECT OF THE FORWARD VELOCITY ON THE CLOSED-LOOP SYSTEM}

The forward velocity of the heavy vehicle continuously varies during operation, especially in the case of an emergency. The rollover of a heavy vehicle often occurs for forward 
Table 7. Signals considered in the frequency and time domains.

\begin{tabular}{lcc}
\hline Signal & Frequency domain & Time domain \\
\hline Normalized load transfers at the front/rear axles $\left(R_{f, r}\right)$ & $\mathrm{X}$ & $\mathrm{X}$ \\
Input currents at the front/rear axles $\left(u_{f, r}\right)$ & $\mathrm{X}$ & $\mathrm{X}$ \\
Roll angle of the sprung mass $(\phi)$ & $\mathrm{X}$ \\
Roll angle of the unsprung masses at the front/rear axles $\left(\phi_{u f, r}\right)$ & $\mathrm{X}$ \\
Roll angle of the suspensions at the front/rear axles $\left(\phi-\phi_{u f, r}\right)$ & $\mathrm{X}$ \\
Side-slip angle $(\beta)$ - Side-slip angle velocity $(\dot{\beta})$ & $\mathrm{X}$ \\
Stability index $(\lambda)$ & $\mathrm{X}$ \\
\hline
\end{tabular}

velocities within 60 to $110 \mathrm{~km} / \mathrm{h}$. In this section, one considers the forward velocity of the heavy vehicle up to $160 \mathrm{~km} / \mathrm{h}$ in order to evaluate the roll stability, as well as to determine the critical velocity at which the actuators reach the physical limits. In what follows, the disturbance is the steering angle $\left(\delta_{f}\right)$ corresponding to a double lane change in Figure 7 [4].

\subsection{Effect of the forward velocity on the roll stability}

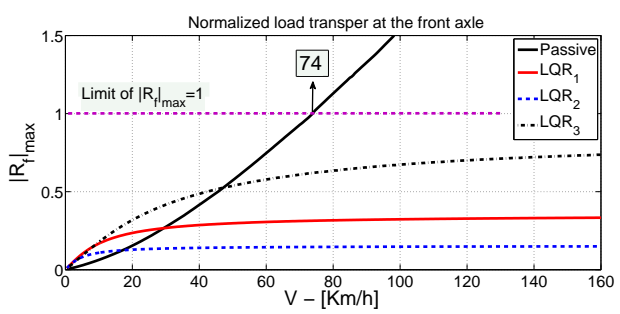

(a)

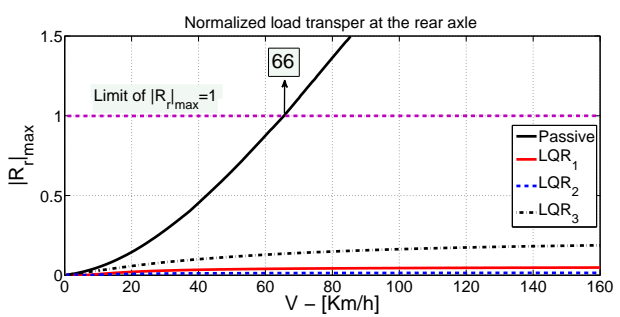

(b)

Figure 11. Effect of the forward velocity on the maximum absolute value of the normalized load transfers at the front (a) and rear (b) axles.

Figures $11 a, b$ show the effect of the forward velocity on the maximum absolute value of the normalized load transfers at the front and rear axles, respectively.

In the passive anti-roll bar case, the maximum absolute values of the normalized load transfers $\left(R_{f, r}\right)$ at the front and rear axles reach the limitations when the forward velocities meet 74 and $66 \mathrm{~km} / \mathrm{h}$, respectively. Meanwhile, in the three $L Q R$ active anti-roll bar controllers case, these indices are always within the limitations. The maximum absolute values of the signals in the case of $L Q R_{2}$ controller are always less than for the $L Q R_{1}$ and $L Q R_{3}$ controllers. It means that the $L Q R_{2}$ controller better improves the roll stability than do the two other controllers. This fulfils consistently the objective of the described controllers.

\subsection{Effect of the forward velocity on the physical constraints of the actuator}

The physical constraints of the actuator are important to assess its applicability on the active anti-roll bar system. We consider the influence of the forward velocity on the actuators to determine their operational limits for the electronic servo-valve and the hydraulic actuator. 


\subsubsection{Electronic servo-valve: spool valve displacement and input current limitations}

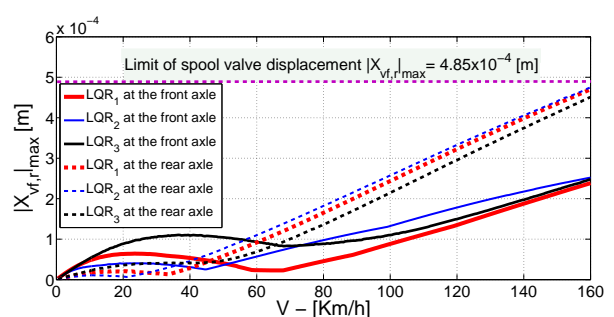

(a)

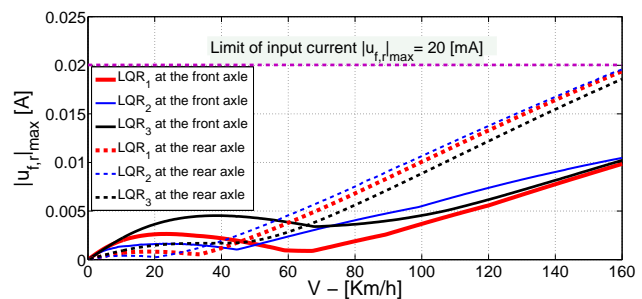

(b)

Figure 12. Influence of the forward velocity on the maximum absolute value of the spool valve displacements (a) and the input currents (b).

Figure $12 a$ shows the effect of the forward velocity on the maximum absolute value of the spool valve displacements at the two axles $\left(X_{v f, r}\right)$. The maximum of the spool valve displacement recommended is $4.85 \times 10^{-4} \mathrm{~m}$ [18]. For the forward velocity of the heavy vehicle up to $160 \mathrm{~km} / \mathrm{h}$, the maximum absolute value of the spool valve displacements stays within the limit.

Figure $12 b$ shows the effect of the forward velocity on the maximum absolute value of the input currents at the two axles $\left(u_{f, r}\right)$. As the maximum of the input current recommended is $20 \mathrm{~mA}$ [18], there is no problem because the input currents always stay within the limit for the forward velocities less than $160 \mathrm{~km} / \mathrm{h}$.

\subsubsection{Hydraulic actuator: load flow and force limitations}

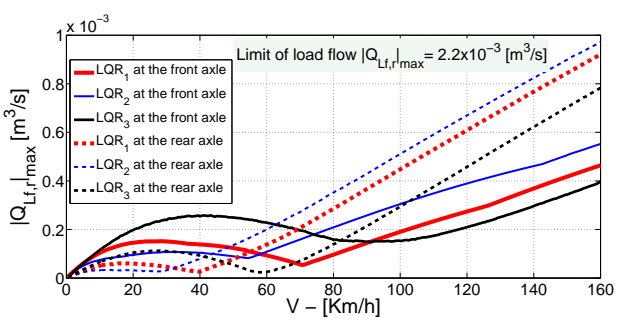

(a)

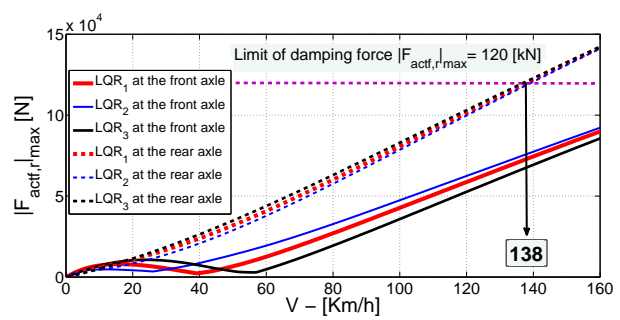

(b)

Figure 13. Influence of the forward velocity on the maximum absolute value of the load flows (a) and the forces (b).

As well, the maximum recommended load flow of oil into the hydraulic actuator is $2.2 \times$ $10^{-3} \mathrm{~m}^{3} / \mathrm{s}$, see McKevitt [7]. Figure $13 \mathrm{a}$ shows that the load flows stay within the limit for the forward velocity up to $160 \mathrm{~km} / \mathrm{h}$.

Figure $13 b$ shows that the maximal admissible limit for the forward velocity of the heavy vehicle is $138 \mathrm{~km} / \mathrm{h}$ in order to ensure that the forces stay within the limit $(120 \mathrm{kN})$ recommended by McKevitt [7].

\section{Conclusion}

This paper proposed an integrated model including four electronic servo-valve hydraulic actuators (two at the front and two at the rear axles) and a linear single unit heavy ve- 
hicle yaw-roll model. Based on this model, an active anti-roll bar control was developed within the $L Q R$ approach, taking into account the normalized load transfer and input current limitations. As shown in the simulation section, the maximal admissible forward velocity of the heavy vehicle obtained $(138 \mathrm{~km} / \mathrm{h})$ ensures that the electronic servo-valve hydraulic actuator operates within its admissible operational limit (forces, load flows, spool valve displacements and input currents). It can then be concluded that the electronic servo-valve hydraulic actuator, controlled by the current, is completely justified for active anti-roll bar control system on the heavy vehicle.

The results obtained in the frequency and time domains show the efficiency of the $L Q R$ active anti-roll bar control approach to improve the roll stability, preventing then the rollover phenomenon of heavy vehicles. The simulations also show the drastic improvements w.r.t. the passive anti-roll bar case. The authors would like to stress that the given methodology allows to solve a multi-objective problem through the definition of an optimal criterion function of several tuning parameters $\rho_{i}$. This tuning facility is an interesting degree of freedom to handle different industrial performance requirements.

In the future, other approaches such as $H_{2} / H_{\infty}$ state feedback control, will be applied to the integrated model, along with the use of observers to assess more deeply the characteristics of the system. Studies on the nonlinear vehicle model and the comparison using nonlinear vehicle simulation packages (such as TruckSim or TruckMaker) are also interesting topics.

\section{References}

[1] Miege A, Cebon D. Design and implementation of an active roll control system for heavy vehicles. In: $6^{\text {th }}$ International Symposium on Advanced Vehicle Control, AVEC 2002; September. Hiroshima, Japan; 2002.

[2] Boada M, Boada B, Quesada A, Gaucha A, Daz V. Active roll control using reinforcement learning for a single unit heavy vehicle. In: 12th IFToMM World Congress; June. Besancon, France; 2007.

[3] Zulkarnain N, Imaduddin F, Zamzuri H, Mazlan SA. Application of an active anti-roll bar system for enhancing vehicle ride and handling. In: 2012 IEEE Colloquium on Humanities, Science \& Engineering Research; December. Kota Kinabalu, Sabah, Malaysia; 2012.

[4] Gaspar P, Bokor J, Szaszi I. The design of a combined control structure to prevent the rollover of heavy vehicles. European Journal of Control. 2004;10(2):148-162.

[5] Sampson D, Cebon D. Active roll control of single unit heavy road vehicles. Vehicle System Dynamics: International Journal of Vehicle Mechanics and Mobility. 2003;40(4):229-270.

[6] Sampson D, Cebon D. Achievable roll stability of heavy road vehicles. In: Proceedings of the Institution of Mechanical Engineers, Part D: Journal of Automobile Engineering; December; Vol. 217. United Kingdom; 2003. p. 269-287.

[7] Sampson DJM. Active roll control of articulated heavy vehicles [dissertation]. University of Cambridge, UK; 2000.

[8] Hsun-Hsuan H, Rama K, Dennis AG. Active roll control for rollover prevention of heavy articulated vehicles with multiple-rollover-index minimisation. Vehicle System Dynamics: International Journal of Vehicle Mechanics and Mobility. 2012;50(3):471-493.

[9] Miege A, Cebon D. Optimal roll control of an articulated vehicle: theory and model validation. Vehicle System Dynamics: International Journal of Vehicle Mechanics and Mobility. 2005;43(12):867-884.

[10] Yu H, Guvenc L, Ozguner U. Heavy duty vehicle rollover detection and active roll control. Vehicle System Dynamics: International Journal of Vehicle Mechanics and Mobility. 2008;46(6):451-470.

[11] Cole DJ. Fundamental issues in suspension design for heavy road vehicles. Vehicle System Dynamics: International Journal of Vehicle Mechanics and Mobility. 2001;35(4-5):319-360.

[12] Gaspar P, Bokor J, Szaszi I. Reconfigurable control structure to prevent the rollover of heavy vehicles. Control Engineering Practice. 2005;13(6):699-711.

[13] Sampson D, Cebon D. An investigation of roll control system design for articulated heavy vehicles. In: 4th International symposium on Advanced Vehicle Control, AVEC1998; September. Nagoya, Japan; 1998. 
[14] Babesse S, Ameddah D. Enhanced active anti-roll control of a single unit heavy vehicle using neuronal network. In: Conference on Advances in Engineering Sciences and Applied Mathematics - $2^{\text {nd }}$ ICAESAM 2014; May. Istanbul, Turkey; 2014.

[15] Gaspar P, Szabo Z, Bokor J. Prediction based combined control to prevent the rollover of heavy vehicles. In: Proceedings of the 13th Mediterranean Conference on Control and Automation; June. Limassol, Cyprus; 2005.

[16] Vu VT, Sename O, Dugard L, Gaspar P. $H_{\infty}$ active anti-roll bar control to prevent rollover of heavy vehicles: a robustness analysis. In: IFAC Symposium on System Structure and Control - $6^{\text {th }}$ SSSC 2016; June. Istanbul, Turkey; 2016.

[17] Merritt H. Hydraulic control systems. John Wiley \& Sons; 1967.

[18] Rafa AHAB, Yahya AF, Rawand EJT. A study on the effects of servo-valve lap on the performance of a closed - loop electrohydraulic position control system. Al-Rafidain Engineering. 2009;17(5):1-14

[19] Renn JC, Wu TH. Modeling and control of a new $1 / 4 \mathrm{~T}$ servo-hydraulic vehicle active suspension system. Journal of Marine Science and Technology. 2007;15(3):265-272.

[20] Vu VT, Sename O, Dugard L, Gaspar P. Active anti-roll bar control using electronic servo-valve hydraulic damper on single unit heavy vehicle. In: IFAC Symposium on Advances in Automotive Control $-8^{\text {th }}$ AAC 2016; June. Norrköping, Sweden; 2016.

[21] Taghirad H, Esmailzadeh E. Automobile passenger comfort assured through LQG/LQR active suspension. Journal of Vibration and Control. 1997;4(5):603-618.

[22] Fergani S, Menhour L, Sename O, Dugard L, D'Andréa-Novel B. LPV/ $H_{\infty}$ suspension robust control adaptation of the dynamical lateral load transfers based on a differential algebraic estimation approach. In: IFAC Symposium on Advances in Automotive Control - $8^{\text {th }}$ AAC 2016; June. Sweden; 2016. 
APPENDIX: The matrices $A, B_{1}$, and $B_{2}$ in the state equation.

From equations (10), (24), the state equation for the integrated model can be written as:

$$
\dot{x}=E^{-1} A_{0} \cdot x+E^{-1} B_{01} \cdot w+E^{-1} B_{02} \cdot u
$$

with the state vector: $x=\left[\beta \dot{\psi} \phi \dot{\phi} \phi_{u f} \phi_{u r} \Delta_{P f} X_{v f} \Delta_{P r} X_{v r}\right]^{T}$, the exogenous disturbance: $w=\left[\delta_{f}\right]^{T}$, the control inputs: $u=\left[\begin{array}{ll}u_{f} & u_{r}\end{array}\right]^{T}$.

The state equation for the integrated model in the LTI state-space representation (25) is given as:

$$
\dot{x}=A \cdot x+B_{1} \cdot w+B_{2} \cdot u
$$

From (38) and (39) the matrices $A=E^{-1} A_{0}, B_{1}=E^{-1} B_{01}$ and $B_{2}=E^{-1} B_{02}$.

Some notations are given as: $Y_{\beta f}=-\mu \cdot C_{f}, Y_{\psi_{f}}=-\mu \cdot \frac{l_{f} \cdot C_{f}}{v}, Y_{\beta r}=-\mu \cdot C_{r}, Y_{\beta}=-\mu \cdot\left(C_{f}+C_{r}\right), Y_{\psi}=$ $\mu \cdot\left(\frac{C_{r} \cdot l_{r}-C_{f} \cdot l_{f}}{v}\right), Y_{\delta}=\mu \cdot C_{f}, Y_{\psi_{r}}=\mu \cdot \frac{l_{r} \cdot C_{r}}{v}, N_{\beta}=\mu \cdot\left(l_{r} \cdot C_{r}-l_{f} \cdot C_{f}\right), N_{\psi}=-\mu \cdot\left(\frac{\left(l_{f}^{2} \cdot C_{f}+l_{r}^{2} \cdot C_{r}\right.}{v}\right), N_{\delta}=\mu \cdot l_{f} \cdot C_{f}, M_{k f}=$ $m_{u f} g h_{u f}-k_{f}-k_{t f}, M_{k r}=-\left(m_{u r} g h_{u r}+k_{r}+k_{t r}\right)$.

leading to the matrices $E, A_{0}, B_{01}$ and $B_{02}$ :

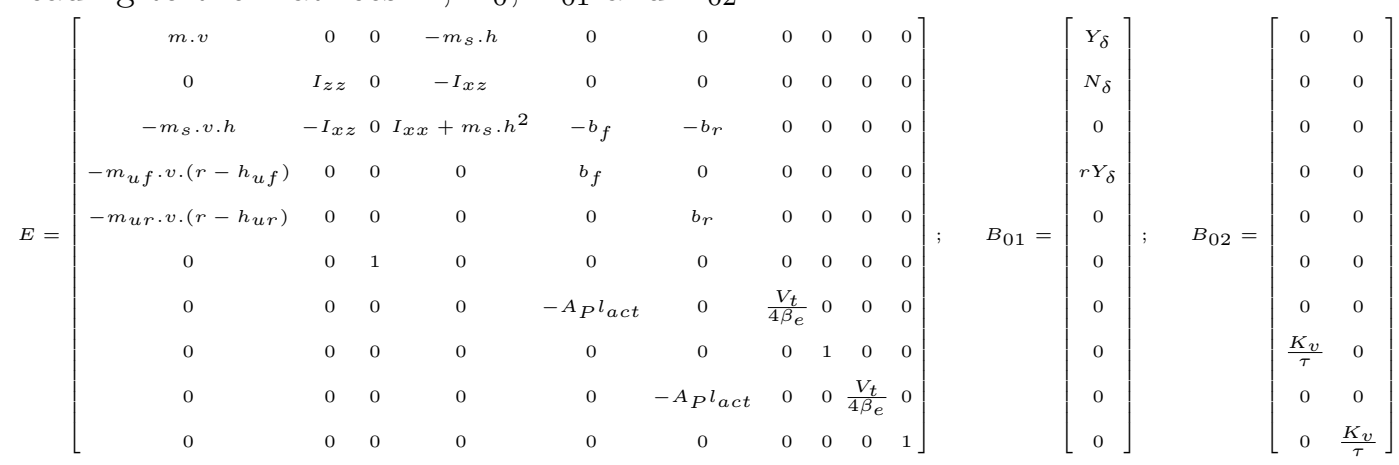

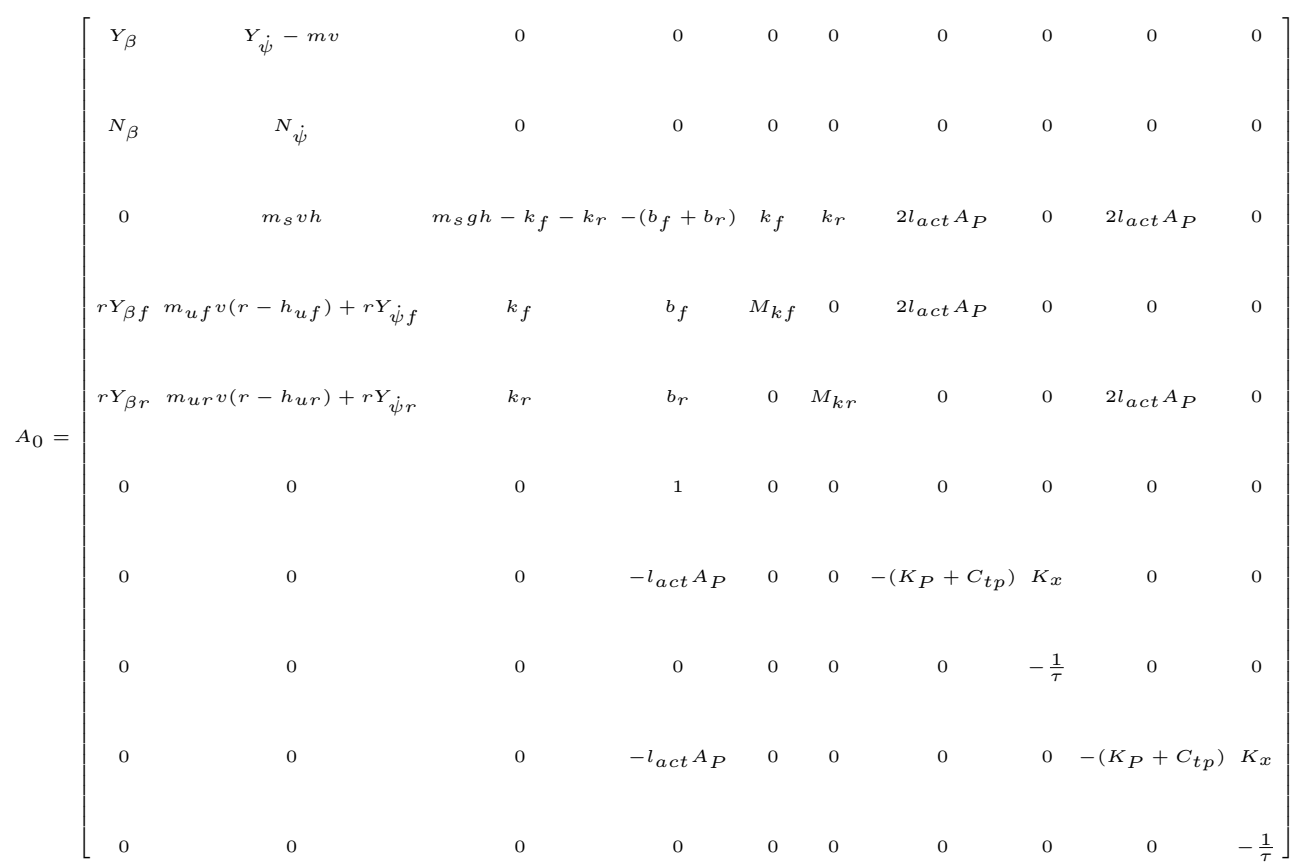

